DOI: https://doi.org/10.47405/mjssh.v5i1.353

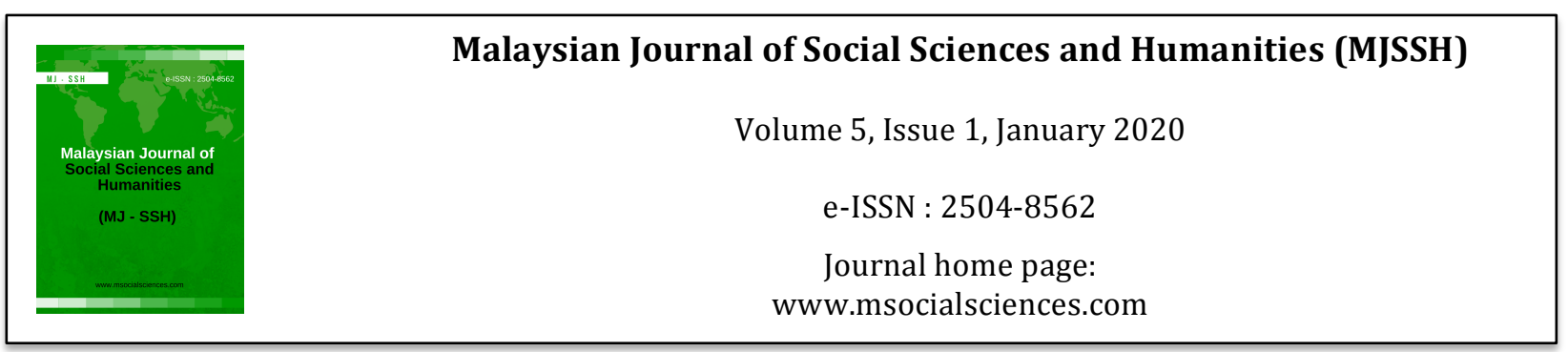

\title{
Bentuk Bantuan Modal Agihan Zakat Asnaf dan Pencapaian Usahawan Asnaf di Malaysia: Kajian Empirikal
}

\author{
Dayang Shobihah Abang Abai', Mohd Daud Awang', Ahmad Nasir Mohd Yusoff', Arfah Ab. Majid", \\ Hadi Hamli2 \\ 1Jabatan Pengajian Kenegaraan dan Ketamadunan, Fakulti Ekologi Manusia, Universiti Putra Malaysia (UPM) \\ ${ }^{1}$ Universiti Putra Malaysia (UPM), Kampus Bintulu, Sarawak
}

Correspondence: Dayang Shobihah Abang Abai (dayangshobihahabangabai.com)

\begin{abstract}
Abstrak
Bantuan modal zakat merupakan salah satu bentuk bantuan yang disalurkan oleh agensi zakat di Malaysia bagi membantu golongan asnaf melibatkan diri dalam dunia perniagaan seterusnya merubah kehidupan mereka lebih baik dari sebelumnya. Oleh itu, terdapat beberapa isu yang timbul seperti berlaku penipuan ke atas bantuan yang diberikan, kegagalan usahawan asnaf dalam perniagaan, serta modal yang tidak mencukupi. Oleh yang demikian, kajian ini adalah bertujuan untuk mengenal pasti bentuk-bentuk bantuan modal yang disediakan oleh Institusi zakat serta mengenal pasti sejauhmanakah pencapaian bantuan modal membantu asnaf dalam perniagaan. Kajian ini telah menggunakan kaedah kualitatif iaitu menemu bual seramai 12 orang informan asnaf dan 5 orang pegawai zakat. Tema yang terhasil daripada persoalan pertama berkaitan dengan bentuk bantuan modal perniagaan ialah bantuan kemahiran, bantuan peralatan dan bantuan kewangan. Manakala tema yang terhasil daripada persoalan yang kedua iaitu pencapaian bantuan agihan zakat, adalah keluar dari kelompok asnaf dan berjaya menjadi pembayar zakat. Secara keseluruhannya hasil dapatan menunjukkan kajian yang dijalankan memuaskan tetapi perlu dipertingkatkan dari segi bantuan modal perniagaan dan pengurusan. Penyelidik berharap agar kajian yang dijalankan dapat membantu institusi zakat dalam mempertingkatkan agihan zakat kepada golongan asnaf serta mempertingkatkan kehidupan mereka ke arah yang lebih baik. Bantuan modal zakat merupakan salah satu bentuk bantuan yang disalurkan oleh agensi zakat di Malaysia bagi membantu golongan asnaf melibatkan diri dalam dunia perniagaan seterusnya merubah kehidupan mereka lebih baik dari sebelumnya. Oleh itu, terdapat beberapa isu yang timbul seperti berlaku penipuan ke atas bantuan yang diberikan, kegagalan usahawan asnaf dalam perniagaan, serta modal yang tidak mencukupi. Oleh yang demikian, kajian ini adalah bertujuan untuk mengenal pasti bentuk-bentuk bantuan modal yang disediakan oleh Institusi zakat serta mengenal pasti sejauhmanakah pencapaian bantuan modal membantu asnaf dalam perniagaan. Kajian ini telah menggunakan kaedah kualitatif iaitu menemu bual seramai 12 orang informan asnaf dan 5 orang pegawai zakat. Tema yang terhasil daripada persoalan pertama berkaitan dengan bentuk bantuan modal perniagaan ialah bantuan kemahiran, bantuan peralatan dan bantuan kewangan. Manakala tema yang terhasil daripada persoalan yang kedua iaitu pencapaian bantuan agihan zakat, adalah keluar dari kelompok asnaf dan berjaya menjadi pembayar zakat. Secara keseluruhannya hasil dapatan menunjukkan kajian yang dijalankan memuaskan tetapi perlu dipertingkatkan dari segi bantuan modal perniagaan dan pengurusan. Penyelidik berharap agar kajian yang dijalankan dapat membantu institusi zakat dalam mempertingkatkan agihan zakat kepada golongan asnaf serta mempertingkatkan kehidupan mereka ke arah yang lebih baik.
\end{abstract}

Kata kunci: usahawan asnaf, modal perniagaan, zakat, institusi zakat, pencapaian 
DOI: https://doi.org/10.47405/mjssh.v5i1.353

\title{
Assistant Type of Capital Zakat Distribution and Achievement of Asnaf Entrepreneur in Malaysia: An Empirical Study
}

\begin{abstract}
Zakat capital assistance is one the support forms provided by Zakat agencies in Malaysia to assist the asnaf get involved in the business world, and to change their lives for the better. There are several of issues emerge such as fraud on the subsidies provided, the failure of entrepreneurs in the business, and insufficient capital. Therefore, the purpose of this study is to identify the types of capital assistance provided by the Zakat Institution and to determine the extent to which the financial assistance achievement is helpful to the business. This study used qualitative methods of interviewing a total of 12 asnaf informants and 5 zakat officials. The themes that arose from the first question related to the type of business capital assistance were skills, equipment and financial assistance. While the theme of the second question, the achievement of the zakat dispersal assistant, is able came out from the asnaf group and became a zakat payer. Generally, the findings show that the study is satisfactory but needs to be improved in terms of business capital and management assistance. Researchers hope that the research conducted will help the zakat institution in increasing the distribution of zakat to asnaf as well as improving their lives in a better way.
\end{abstract}

Keywords: asnaf entrepreneur, business capital, zakat, institution of zakat, achievement

\section{Pengenalan}

Pada era kini, kemiskinan merupakan antara masalah utama yang membelenggu kebanyakan negaranegara membangun di dunia. Sehubungan itu, di Malaysia, hal ini telah menjadi agenda yang diberikan keutamaan oleh pihak kerajaan sejak 13 Mei 1969 (Syafinas, 2014). Pihak kerajaan telah memperkenalkan pelbagai dasar dan program untuk membantu masyarakat terutamanya golongan B40 menjalani kehidupan yang lebih baik dan selesa. Sehubungan itu juga, Institusi zakat turut tidak ketinggalan dalam memainkan peranan penting bagi membantu ekonomi umat Islam di Malaysia. Oleh itu, Zakat berfungsi sebagai salah satu mekanisme pembasmian kemiskinan kerana ia mampu memenuhi keperluan asnaf sama ada dalam bentuk bantuan tetap bulanan atau suntikan modal bagi membolehkan mereka berdikari. (al-Qaradawi, 1995).

Sehubungan itu, usahawan asnaf merupakan suatu konsep yang baru diteroka di Malaysia. Oleh yang demikian kita dapat lihat, tidak semua pihak berkuasa agama negeri yang mempunyai badan khusus mentadbir urusan zakat. Penubuhan pusat-pusat pungutan zakat telah membantu pengurusan berkaitan zakat dan asnaf dengan lebih berkesan termasuklah dalam aspek mewujud dan membangun usahawan asnaf. Aktiviti membangunkan asnaf untuk menjadi usahawan dijalankan secara giat hanya dibeberapa negeri iaitu Wilayah Persekutuan, Selangor, Negeri sembilan dan Pulau Pinang. Secara umumnya, bantuan yang diberikan oleh institusi zakat kepada para asnaf untuk membangunkan perniagaan telah pun bermula sejak tahun 1990 an lagi.

Dengan itu, Institusi zakat mula mengorak langkah dengan melaksanakan program jangka panjang bagi merealisasikan agenda pembasmian kemiskinan kerana isu kemiskinan perlu ditangani secara berterusan dan bukannya pada musim-musim tertentu sahaja. Oleh itu, terdapat dua bentuk bantuan zakat yang disediakan oleh pihak institusi zakat iaitu bantuan produktif dan bantuan bukan produktif. Bantuan produktif merujuk kepada bantuan modal sama ada dalam bentuk wang tunai atau pun peralatan bagi membantu golongan asnaf mengubah kehidupan mereka ke arah yang lebih baik. Bantuan ini biasanya diberikan dalam bentuk jangka panjang. Bantuan bukan produktif pula bersifat jangka pendek bagi membantu asnaf meneruskan kelangsungan hidup mereka dengan memenuhi keperluan asas yang diperlukan seperti bantuan perubatan, saran bulanan, makanan, sewa rumah dan lain-lain (Fatimah, 2014). 
Dalam usaha mentransformasikan asnaf daripada kelompok bukan produktif kepada kelompok produktif, pihak institusi zakat telah memperkenalkan bantuan modal buat asnaf yang berminat untuk menceburi sektor keusahawanan. Ia bertujuan untuk membantu golongan asnaf yang berminat dalam bidang keusahawanan atau perniagaan iaitu dari aspek modal perniagaan. Bantuan ini juga membantu asnaf mempertingkatkan lagi perniagaan mereka bagi yang telah memulakan perniagaan. Menurut Wan Sabri (2009), Majlis Agama Islam Negeri Sembilan merupakan institusi zakat pertama yang memperkenalkan bantuan seumpama ini di Malaysia iaitu pada tahun 2004. Usaha ini kemudiannya diikuti oleh institusi zakat lain seperti di Selangor, Wilayah Persekutuan dan Terengganu. Selangor dan Wilayah Persekutuan dilihat lebih aggresif dalam melaksanakan program ini berkemungkinan disebabkan jumlah kutipan dana zakatnya yang lebih tinggi serta sumber kakitangan yang mencukupi dan berkemahiran dalam mengendalikan program usahawan asnaf ini (Azman, 2014).

\section{Sorotan Literatur}

Pada tahun 1971 Penubuhan Dasar Ekonomi Baru (DEB) telah menyemarakkan sektor keusahawanan berkembang menjadi suatu bidang kerjaya yang utama dalam pembangunan masyarakat dan ekonomi. (Suhaila et al., 2016). Perkara ini bertepatan dengan matlamat utama pelaksanaan dasar ini iaitu pembasmian kemiskinan dan penstrukturan semula masyarakat bagi mewujudkan keseimbangan ekonomi antara kaum. Golongan usahawan memainkan peranan penting dalam menggerakkan perubahan dalam struktur ekonomi masyarakat sesebuah negara (Ab. Aziz, 2010). Menurut Sanep, (2012) potensi sebagai usahawan bukanlah sesuatu yang boleh diwujudkan dalam diri individu secara tiba-tiba namun perlu melalui usaha dan komitmen yang jitu. Antara ciri-ciri perlu ada pada setiap usahawan adalah keberanian mengambil risiko, pemikiran kreatif dan inovatif, bijak menghidu peluang, berkeyakinan tinggi, berpandangan jauh, berorientasikan perancangan serta mampu menerima teguran dan kritikan membina Sehubungan dengan itu juga, anjakan paradigma yang telah dilakukan oleh beberapa institut zakat di Malaysia telah merancakkan lagi agenda pemerkasaan ekonomi golongan asnaf. Pelaksanaan program pembangunan ekonomi yang dirangka khusus buat golongan asnaf bertujuan menyediakan platform buat mereka yang berminat untuk menceburkan diri dalam bidang perniagaan dengan pemberian bantuan sokongan berupa modal perniagaan, modal pusingan, kursus kemahiran dan sebagainya. Hasilnya, matlamat untuk melahirkan golongan usahawan asnaf yang berdaya saing mampu direalisasikan.

Usahawan asnaf secara umumnya dapat difahami sebagai kelompok asnaf khususnya dalam kumpulan fakir dan miskin yang ingin ditransformasikan daripada asnaf bukan produktif menjadi asnaf produktif menerusi platform keusahawanan. Kelompok ini akan diberikan bantuan dan bimbingan yang diperlukan bagi membolehkan mereka bergelar usahawan (Sanep, 2012). Isma Addi (2007) mendefinisikan usahawan asnaf sebagai individu yang perlu melalui suatu proses penciptaan usaha niaga bagi memastikan mereka mampu memikul bebanan tanggungjawab sebagai usahawan serta mempunyai keyakinan untuk menyertai bidang perniagaan dengan rangsangan berupa dorongan dan bantuan daripada institusi zakat. Proses penciptaan usaha niaga merupakan fasa atau peringkat tertentu yang perlu dilalui sebelum golongan ini menjadi usahawan dengan bantuan, dorongan dan bimbingan daripada institusi zakat di negeri masing-masing. Namun begitu, beberapa kekurangan dan halangan yang mampu merencatkan proses ini perlu ditangani terlebih dahulu oleh peserta yang terlibat seperti kekurangan modal, kekurangan pengetahuan pengurusan, kekurangan kemahiran dan pekerja berbakat, kekurangan keupayaan dan sukar mendapat khidmat pakar serta kekurangan kualiti sebagai usahawan berjaya (Siti Norbay, 2011).

Selain itu, pembiayaan modal merupakan aspek yang paling rumit dalam memulakan perniagaan (Ang, 1991; Ang 1992). Kekurangan pembiayaan merupakan punca utama sebuah perusahaan kecil gagal. Tanpa pembiayaan yang mencukupi seseorang usahawan kecil tidak mampu untuk membeli dan menyenggarakan kemudahan, mengambil pekerja, menghasilkan dan memasarkan produk (Megginson, 2000). Kajian yang telah dibuat oleh Norsidah (1999) berkaitan kecukupan saiz bantuan modal, menyatakan bahawa faktor kecukupan saiz modal mempunyai hubungan yang positif dengan kejayaan sesebuah perniagaan. Manakala, menurut Rohaizat (2000), berdasarkan satu kajian oleh Lussuer terhadap seratus orang usahawan Amerika Syarikat yang telah gagal dalam perniagaan mereka 
menunjukkan bahawa mereka gagal akibat dari faktor kekurangan modal, kos tetap yang tinggi dan masalah kemelesetan ekonomi.

Bentuk bantuan zakat yang dikaji lebih menjurus kepada bantuan yang diterima dalam bentuk tidak produktif seperti bantuan saraan bulanan yang menunjukkan bahawa bantuan berkenaan masih belum dapat memberikan impak yang mencukupi dari segi meningkatkan taraf kehidupan golongan fakir dan miskin (Hairunnizam et. al., 2001; Muhamad Loqman \& Golam, 1998; Imran \& Abu Nasar, 2001) walaupun terdapat juga kajian yang menunjukkan ia berjaya mengurangkan kemiskinan dan mengurangkan jurang pendapatan (Fuadah, 2004; Patmawati, 2005). Selain itu, kajian yang dijalankan mengenai faktor yang menyumbang kepada kejayaan perniagaan kecil oleh penerima zakat adalah melihat dari segi faktorfaktor demografi (umur, jantina, taraf pendidikan, saiz keluarga), jenis bantuan, jumlah bantuan, aspek latihan, kerjasama agensi, pemantauan dan pengurusan institusi zakat (Noor Ghani et. al., 2002; Ahmad Fuad, 2006; Supardi, 2005; Abu Sufian, 2006).

Kajian oleh Supardi (2005) juga telah menunjukkan penemuan yang sama. Beliau telah melakukan kajian terhadap penerima bantuan zakat menerusi Program Komuniti Pembangunan Ekonomi (Community Economic Development (CED)) di Semarang, Indonesia. Penerima bantuan zakat untuk menjalankan perniagaan kecil. Hasil kajian mendapati bahawa bantuan modal perniagaan berkenaan terlalu kecil jumlahnya dan tidak berupaya mengeluarkan mereka dari kemiskinan (diukur daripada jumlah peningkatan pendapatan) malahan program ini bersifat konservatif yang tidak berupaya meningkatkan kemajuan diri dalam aspek sosial dan political empowerment. Kajian mendapati bahawa kegagalan bantuan ini mencapai matlamat adalah didorong oleh faktor kekurangan bimbingan, latihan, pemantauan dan pengurusan badan yang menguruskan bantuan berkenaan, di samping sikap peserta bantuan yang tidak berdisiplin dan menyalahgunakan bantuan untuk tujuan lain.

Menerusi kajian Rosbi et. al. (2008) mengenai analisis perbandingan pemberian bantuan modal zakat berbanding bantuan yang diberikan oleh Amanah Ikhtiar Malaysia (AIM) dan Yayasan TEKUN Nasional (TEKUN), didapati bahawa perbezaan paling ketara adalah dari aspek pemantauan yang mana bagi bantuan modal zakat tidak dilakukan pemantauan secara berkala dan sistematik. Ia dianggap sebagai bantuan berciri ihsan yang menjadi hak golongan fakir miskin. Berjaya atau gagal tidak menjadi persoalan penting. Maka, kemungkinan pada akhirnya penerima bantuan mempunyai motivasi yang rendah, tiada komitmen dan berakhir dengan kegagalan. Kesimpulannya, berdasarkan pandangan dan hasil kajian di atas didapati antara ciri dan faktor penting yang mempengaruhi kejayaan sesuatu perusahaan atau perniagaan yang dijalankan adalah faktor dan ciri keperibadiannya (faktor dalaman) dan dibantu dengan faktor luaran lainnya.

\section{Kenyataan Masalah}

Terdapat beberapa persoalan kajian yang dibincangkan, antaranya, adakah bantuan modal perniagaan ini benar-benar membantu usahawan asnaf. Seterusnya, objektif kajian penyelidik melihat apakah bentuk bantuan yang diberikan kepada usahawan asnaf serta melihat sejauhmanakah pencapaian selepas bantuan diberikan. Justeru itu, penyelidik berharap agar kajian ini menjadi panduan kepada pihak yang terlibat dalam melaksanakan sistem pengagihan zakat secara berkesan dan efisien. Terdapat beberapa permasalahan isu perlaksanaan agihan zakat yang berlaku di seluruh Institusi Zakat di Malaysia berdasarkan beberapa tulisan seperti:

Kajian yang dijalankan oleh Sanep Ahmad (2012) kegagalan usahawan asnaf ini telah menyebabkan masyarakat hilang kepercayaan terhadap institusi zakat kerana dianggap telah gagal melaksanakan agihan wang zakat. Institusi zakat dikatakan gagal melaksanakan tanggungjawab semata-mata kerana masih ada kemiskinan dalam masyarakat. Tanggapan negatif ini menyebabkan Institusi zakat mengalami masalah dan perlu di perbaiki dari masa ke semasa.

Kajian yang dijalankan oleh Md Hairi Md Hussien (2009) mendapati bahawa pengurusan institusi zakat di Malaysia masih kurang efisien. Bahkan, terdapat sesetengah aduan dibuat kepada sesetengah institusi zakat berkaitan dengan proses pengagihan Dana zakat (Hairunnizam et.al, 2008; Harian Metro 
March 12). Ini berikutan skim agihan zakat yang diberikan kepada lapan golongan asnaf sahaja tanpa melihat kepada kemaslahatan.

Menerusi kajian Supardi (2005) pula, menunjukkan penemuan yang sama. Beliau menjalankan kajian terhadap penerima bantuan modal perniagaan menerusi satu program iaitu Program Komuniti Pembangunan Ekonomi di Semarang, Indonesia. Hasil dapatan kajian ini, mendapati bahawa bantuan modal perniagaan yang diberikan tidak mampu mengeluarkan mereka daripada kemiskinan. Malahan program ini bersifat konservatif yang tidak berupaya meningkatkan kemajuan diri dalam aspek sosial dan politik. Kegagalan bantuan ini mencapai matlamat adalah didorong oleh faktor kekurangan bimbingan, latihan dan juga pemantauan. Daripada kajian ini, timbul isu kekurangan latihan, bimbingan, pemantauan dan menyebabkan masalah kepada agihan bantuan.

Kajian yang dijalankan oleh Rosbi (2008) pula, perbandingan bantuan agihan zakat dan bantuan yang diberikan oleh Amanah Ikthiar Malaysia (AIM) dan Yayasan TEKUN Nasional, di dapati terdapat perbezaan yang ketara dari aspek pemantaun yang mana pemantauan daripada zakat tidak dilakukan dengan sistematik dan berkala,Manakala AIM dan TEKUN membuat pemantauan secara sistematik dan berkala. Akhirnya penerima bantuan mempunyai motivasi yang rendah, tiada komitmen dan berakhir dengan kegagalan. Berdasarkan daripada kajian di atas timbul satu isu di mana aspek pemantauan sangat penting dalam sesuatu perniagaan agar perniagaan yang dijalankan berjalan dengan lancar. Selain itu faktor keperibadian juga penting dalam menjalankan perusahaan atau perniagaan. Secara keseruhannya, hasil daripada kajian-kajian lepas terdapat beberapa penyelewengan telah berlaku, dengan itu penyelidik berharap agar kajian seterusnya dapat merungkai dan membantu Institusi zakat dan asnaf menyelesaikan masalah yang dihadapi oleh mereka.

\section{Objektif kajian}

Secara amnya, kajian ini dijalankan adalah untuk mengenal pasti sejauhmanakah pencapaian bantuan modal perniagaan kepada usahawan asnaf di Institusi zakat, Malaysia

i. Apakah bentuk bantuan modal perniagaan usahawan asnaf yang dijalankan di Institusi Zakat, Malaysia

ii. Sejauhmanakah pencapaian agihan bantuan modal perniagaan terhadap usahawan asnaf

\section{Metod Kajian}

Berdasarkan kepada tajuk penyelidikan yang dicadangkan, penyelidik telah memilih kajian yang berbentuk kualitatif di mana ianya menggunakan kaedah temubual. Metodologi penyelidikan tertumpu kepada kaedah-kaedah berikut: Kaedah Dokumentasi, kaedah ini bererti cara pengumpulan data dengan melakukan studi atau kajian terhadap dokumen-dokumen yang ada hubungannya dengan masalah yang diteliti dan dikaji yang meliputi kajian lepas dan perbahasan hukum syarak. Ini termasuklah mengkaji bahan-bahan bercetak seperti buku-buku, jurnal, kertas-kertas kerja, laporan-laporan, hasil penyelidikan sebelum ini, majalah-majalah, akhbar-akhbar dan sebarang bahan bertulis yang berkaitan dengan tajuk kajian. Kaedah Temubual (Interview) kaedah ini adalah cara pengumpulan data dengan mengadakan temubual semi berstruktur terhadap pegawai institusi zakat dan golongan asnaf iaitu usahawan asnaf.

\section{Hasil kajian}

Hasil kajian menunjukkan bahawa terdapat beberapa tema yang dihasilkan daripada temu bual dengan informan pegawai zakat dan usahawan asnaf .Dapatan kajian dari persoalan yang pertama mendapati bentuk-bentuk bantuan yang diberikan kepada usahawan asnaf adalah seperti bantuan peralatan iaitu mesin-mesin besar seperti mesin pemprosesan mee kuning, mesin jahit dan juga bantuan dari segi modal kewangan serta bantuan kemahiran. Manakala persoalan yang kedua berkaitan pencapaian bantuan modal perniagaan, tema yang terhasil adalah keluar dari status asnaf dan berjaya menjadi 
DOI: https://doi.org/10.47405/mjssh.v5i1.353

pembayar zakat. Kesemua tema ini adalah hasil daripada temu bual dengan informan pegawai zakat dan usahawan asnaf. Rajah 1 di bawah menunjukkan ringkasan daripada hasil dapatan kajian yang dijalankan.

BENTUK BANTUAN MODAL AGIHAN ZAKAT ASNAF DAN PENCAPAIAN USAHAWAN ASNAF DI MALAYSIA SATU KAJIAN EMPIRIKAL

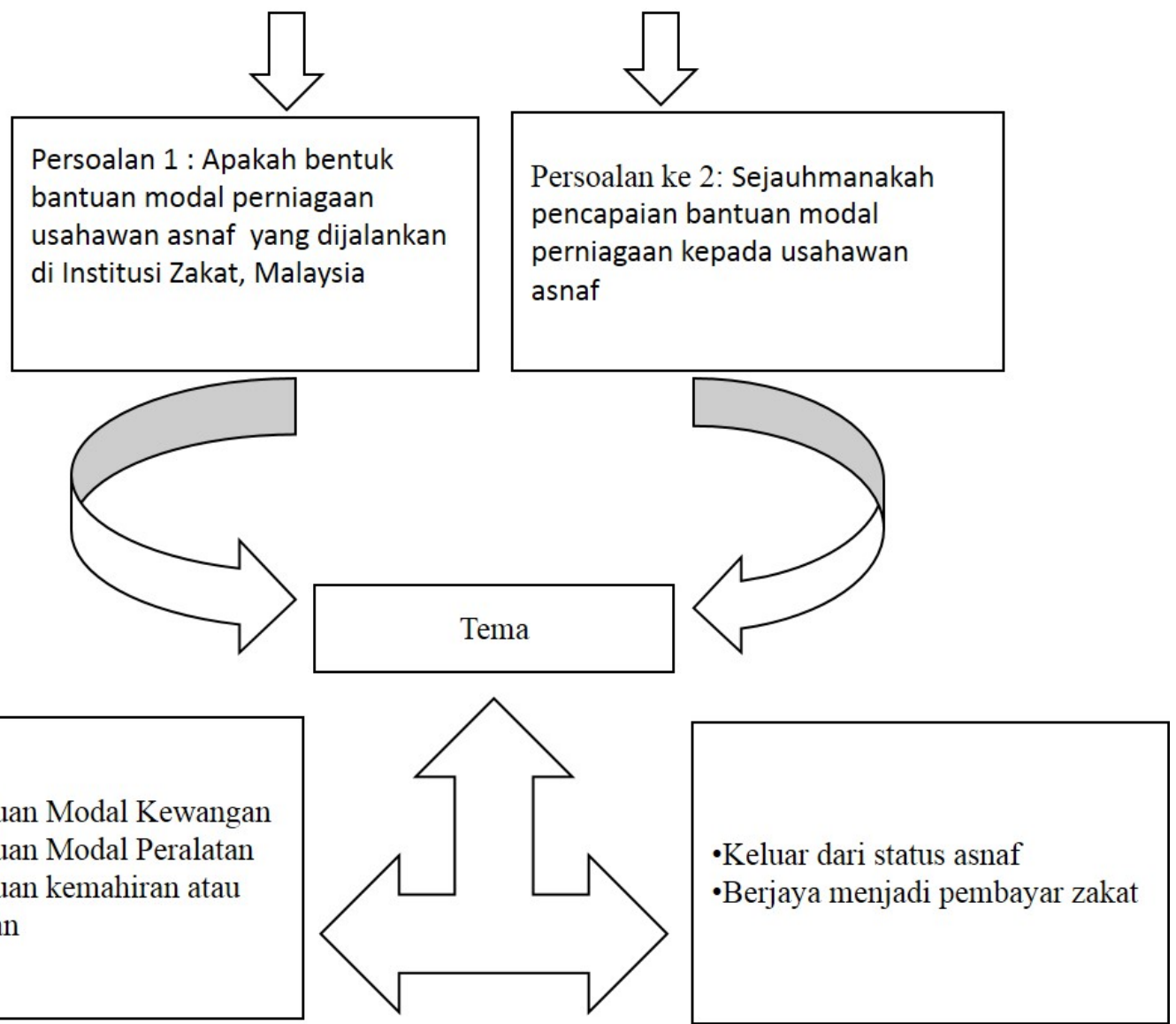

1. Bantuan Modal Kewangan

2. Bantuan Modal Peralatan

3. Bantuan kemahiran atau latihan

-Keluar dari status asnaf

-Berjaya menjadi pembayar zakat

\section{Kesimpulan}

Secara ringkasnya, bantuan zakat sangat erat kaitannya dengan kesejahteraan masyarakat di mana ia telah ditetapkan oleh Allah dengan matlamat utama sebagai satu bentuk jaminan keselamatan sosial bagi mereka yang miskin dan memerlukannya, membangunkan pertumbuhan ekonomi yang seimbang dalam masyarakat, dan juga sebagai satu bentuk penyucian jiwa. Dari segi sosioekonomi, peranan zakat memiliki dua implikasi iaitu agihan pendapatan (zakat) dan membasmi kemiskinan.Sehubungan itu juga, Islam tidak menghendaki kekayaan itu dimonopoli oleh seseorang atau segelintir orang sahaja, melainkan ia harus beredar di kalangan masyarakat lain khususnya mereka yang lebih memerlukannya. Penyelidik berharap agar kajian ini dapat membantu Institusi zakat dalam menangani masalah kemiskinan di negara ini.

\section{Rujukan}

Ahmad Mahdzan Ayob. (1989). Perancangan dan Penilaian Projek Pembangunan. Kuala Lumpur Dewan Bahasa dan Pustaka

Ahmad Fadzly Esa. (2016). LZS Sasar Kutipaan, Agihan Zakat RM645 juta. Berita Harian Online, 4 Februari. 
DOI: https://doi.org/10.47405/mjssh.v5i1.353

Azman, Ab Rahman. Mohammad, Alias, Syed Mohd Najib, Syed Omar. (2012). Zakat Institution in Malaysia: Problems and Issues. GJAT. Vol 2(1), hlm 35-41

Fatimah Salwa Abd Hadi, Nurhanie Mahjom dan Zuriadah Ismail. (2014). Prestasi Bukan Kewangan dan Persepsi Usahawan Asnaf Zakat Terhadap Program Pembangunan Ekonomi Melalui Agihan Zakat Produktif. Prosiding, International Conference on Masjid.

Fatimah Salwa Abd. Hadi, Nurhanie Mahjom, Azila Abdul Razak, Mohd Yahya Mohd Hussin dan Fidlizan Muhammad. (2015). Prestasi Usahawan Asnaf Zakat Terhadap Program Pembangunan Ekonomi di Lembaga Zakat Selangor. The Journal of Management and Science, Vol. 1 No. 1: 110.

Hairunnizam, W., Mohd Ali, M. N., \& Sanep, A. (2005). Kesedaran membayar zakat: Apakah faktor penentunya? IJMS, 12(2), 171-189.

Hairunnizam, W., Sanep, A., \& Radiah, A. K. (2009). Pengagihan zakat oleh institusi zakat di Malaysia: Mengapa masyarakat Islam tidak berpuas hati? Jurnal Syariah, 17(1), 89-112.

Imtiazi I.A. (2000), Introduction dalam: I.A. Imtiazi et al. (eds.), Management of Zakah in Modern Muslim Society, Jeddah: IRTI/IDB, pp. 11-28.

Kets de Vries \& Manfred F.R. (1977). The entrepreneuriel personality: A person at the cross roads. Journal of Managerial Studies, 14(1), 34-57.

Lembaga Zakat Selangor (LZS) Laporan Pengurusan Zakat Selangor 2013. Selangor: Lembaga Zakat Selangor (2013)

Lembaga Zakat Selangor (LZS) Laporan Pengurusan Zakat Selangor 2012. Selangor: Lembaga Zakat Selangor (2012)

Lembaga Zakat Selangor. (2015). Program Pembangunan Ekonomi (Lembaga Zakat Selangor). Shah Alam: Lembaga Zakat Selangor.

Mannan, M.A. (2003). Public Sector Management of Zakat dalam Hannan S.A (eds.). Zakat and Poverty Alleviation. Dhaka: Islamic Economics Research Bureau.

Rosbi bt Abd Rahman. (2011). Keberkesanan Skim bantuan modal Zakat Ke Arah Peningkatan Taraf Sosioekonomi Golongan Asnaf Fakir dan Miskin. Tesis Doktor Falsafah, Fakulti Ekonomi dan Pengurusan, Universiti Kebangsaan Malaysia.

Rossi, P.H., Lipsey, M.W \& Freaman, H.E. (2004). Evaluation A Systematic Approach. Seventh edition. California: Sage Publishers, Inc.

Sanep, A., \& Hairunnizam, W. (2004). Kesan prestasi agihan oleh institusi formal ke atas kepatuhan membayar zakat. Kertas kerja dibentangkan di Pascasidang SeminarKebangsaan Fakulti Ekonomi \& Perniagaan, Kuala Lumpur.

Sanep, A., \& Hairunnizam, W. (2005). Persepsi agihan zakat dan kesannya terhadap pembayara zakat melalui institusi formal. Jurnal Ekonomi Malaysia, 39, 53-69.

Sadeq, A.H.M. (1988). lslamic Perspective on Monetary and Fiscal Policies and Their Implications on Economic Development. Analisis 3(1\&2): 123-140

Sanep Ahmad. (2012). Membangun Keusahawanan Asnaf: Analisis Konsep Model Pemindahan Teknologi. Prosiding, Persidangan Kebangsaan Kebangsaan Ekonomi Malaysia ke-7.

Suhaila Nadzri, Nur Shakina Mohd Sultan dan Nuzul Akhtar Baharudin. (2016). Kecenderungan Pelajar Asnaf dalam Menceburi Dunia Keusahawanan. Prosiding, 3rd International Conference on Management \& Muamalah.

Xavier, John Antony. (2000). Effective Evaluation: A Practical Guide. Kuala Lumpur: National Institute of Public Administration (INTAN).

Zainal Abidin Arshad. (1992). Kemiskinan: Kajian Keberkesanan Program-program Kerajaan di Perlis. Tesis Sarjana Ekonomi, Fakulti Ekonomi dan Perniagaan, Universiti Kebangsaan Malaysia. 